\title{
涡轮低频大功率声波吹灰器在 MGGH 烟气冷却器中的应用
}

\section{Application of Turbine Low Frequency and High Power Acoustic Soot Blower in MGGH Flue Gas Cooler}

\author{
郑华勇 \\ Huayong Zheng \\ 厦门华夏国际电力发展有限公司 中国·福建 厦门 361026 \\ Xiamen China International Power Development Co.Ltd., Xiamen, Fujian, 361026, China
}

\begin{abstract}
摘 要: MGGH 烟气冷却器的运行中堵灰现象较为普遍, 导致 MGGH 烟气冷却器换热能力下降。论文结合设备概况、烟气性 质、锅炉点火及助燃采用 0 号轻柴油、主要设计性能指标、设备运行现状等,提出了 MGGH烟冷器吹灰系统未改造前存在的 问题, 论述了设备吹灰器改造进程。经过实例得出, 设备吹灰器改造后取得的效果良好。
\end{abstract}

\begin{abstract}
During the operation of MGGH flue gas cooler, ash blockage is common, which leads to the decrease of heat transfer capacity of MGGH flue gas cooler. Based on the general situation of the equipment, the nature of flue gas, the use of No. 0 light diesel oil for boiler ignition and combustion supporting, the main design performance indexes and the operation status of the equipment, the paper puts forward the problems existing in the soot blowing system of MGGH flue gas cooler before transformation, and discusses the transformation process of the soot blower of the equipment. Through the example, it is concluded that the effect is good after the retrofit of soot blower.
\end{abstract}

关键词: MGGH 烟气冷却器; 涡轮低频大功率声波吹灰器; 存在问题;改造; 成果

Keywords : MGGH flue gas cooler; turbine low frequency and high power acoustic soot blower; existing problems; transformation; achievement

DOI : $10.36012 /$ peti.v2i3.2076

\section{1 引言}

\section{1 设备概况}

华夏电力位于厦门海沧建港路 702 号, $1^{\#} \sim 4^{\#}$ 机组均为 $300 \mathrm{MW}, 4$ 台锅炉均由中国上海锅炉厂设计制造, 为亚临界 压力、一次中间再热、控制循环汽包炉。 $1^{\# 、} 2^{\#}$ 锅炉型号为 SG-1025/18.3-M832。3 、4 锅炉型号为 SG1025/17.47-M895。

一、二期 MGGH 分别于 2015-2016 年完成现场改造; MGGH 系统由烟气冷却器、烟气再热器、辅助蒸汽系统、声波 吹灰系统、氮气稳压罐、循环水泵等部分组成。MGGH 烟气冷 却器壳体材料 $\mathrm{ND}(09 \mathrm{CrCuSb})$ 钢, 壳体厚度 $6 \mathrm{~mm}$, 低温段换热 面材质采用 $60 \% 316 \mathrm{~L}$ 不锈钢。MGGH 烟气冷却器安装在除 尘器人口的水平烟道上, 每台炉安装 4 台烟气冷却器, 从固
定端往扩建端即 $1^{\#}$ 炉往 $4^{\#}$ 炉方向上起分别命名为 A1/A2/ B1/B2 MGGH 烟气冷却器。其作用是通过循环水系统将从冷 却器处吸收的烟气热量, 在再热器部分加热净烟气, 以达到 提高净烟气排烟温度, 消除烟图白烟的目的。

MGGH 烟气冷却器: 采用 $\mathrm{H}$ 型翅片管, 基管壁厚 $5 \mathrm{~mm}$, 肋片厚度 $2.5 \mathrm{~mm}$ 。由于原设计声波吹灰器采用膜片和共振腔 形式, 未达到设计要求, 堵灰严重。MGGH 烟气冷却器人口烟 温 $130^{\circ} \mathrm{C}$, 出口烟温 $90^{\circ} \mathrm{C}$, 并且 MGGH 烟气冷却器处于 SCR 后部, 此温度下氨逃逸后易形成硫酸氢氨, 加剧 MGGH 烟气 冷却器堵塞 ${ }^{[1,2]}$ 。

MGGH 烟气冷却器后部引风系统由 2 台引风机+1 台增 压风机组成。 


\section{2 烟气性质}

MGGH 烟气冷却器入口烟气露点温度: $100^{\circ} \mathrm{C}$;

MGGH 烟气冷却器入口烟气含尘量: $22 \mathrm{~g} /\left(\mathrm{N} \cdot \mathrm{m}^{3}\right)$ 。

\section{3 锅炉点火及助燃采用 0 号轻柴油}

0 号轻柴油特性见表 1 。

表 10 号轻柴油特性

\begin{tabular}{c|c|c|c}
\hline 序号 & 项目 & 数值 & 备注 \\
\hline 1 & 低位发热量 $/(\mathrm{kJ} / \mathrm{kg})$ & 41870 & \\
\hline 2 & 运行秥度/厘沱 & $3.0 \sim 3.8$ & $20^{\circ} \mathrm{C}$ 时 \\
\hline 3 & 灰分含量 $/ \%$ & $<0.025$ & \\
\hline 4 & 硫含量 $/ \%$ & $<0.2$ & \\
\hline 5 & 十元烷含量 $/ \%$ & $<50$ & \\
\hline 6 & 闭口闪点 $/{ }^{\circ} \mathrm{C}$ & $<65$ & \\
\hline 7 & 凝固点 $/{ }^{\circ} \mathrm{C}$ & 0 & \\
\hline
\end{tabular}

\section{4 主要设计性能指标}

(1) MGGH 烟气冷却装置能够满足烟温从 $130^{\circ} \mathrm{C}$ 降到 $87^{\circ} \mathrm{C}$, 同时满足设计工况下换热器换热能力不小于 $43^{\circ} \mathrm{C}$ 。

(2)辅助蒸汽加热系统不投运, 设计工况下, MGGH 烟气 再热器装置能够满足将烟温从 $25^{\circ} \mathrm{C}$ 升至大于 $63^{\circ} \mathrm{C}$, 同时 MGGH 烟气再热器升温能力不低于 $35^{\circ} \mathrm{C}$ 。

(3)辅助加热装置投运, 在任何工况下, MGGH 系统满足 将入口烟温从最低 $25^{\circ} \mathrm{C}$ 升至 $63^{\circ} \mathrm{C}$ 以上的能力。

(4)MGGH 系统投运后, 设计工况下, 烟气系统阻力 (含 MGGH 烟气冷却装置、MGGH 烟气再热装置及进出口喇叭口 等)不大于 $900 \mathrm{~Pa}$; $\mathrm{MGGH}$ 系统水侧整体压降不大于 $0.5 \mathrm{MPa}$ 。

\section{5 设备运行现状}

实际运行工况为烟气冷却装置在投运约 60d 差压超过 $1.05 \mathrm{kPa}$ (最大量程), 引风机出力受限引发喘振, 部分机组无 法带满负荷 300MW (如 $1^{*}$ 机组), 出现机组出力受限 (285MW), 改烧好煤机组才能带满负荷; 烟气温降约 $20^{\circ} \mathrm{C}$ (原设计值为 $43^{\circ} \mathrm{C}$ ), 净烟气温度约 $56^{\circ} \mathrm{C}$, 低于设计值 $63^{\circ} \mathrm{C}$ 。

\section{$2 M G G H$ 烟冷器吹灰系统未改造前存在问题}

(1)改造前各炉运行约 60d 后, 烟气冷却器差压经常超过 $1.05 \mathrm{kPa}$ (最大量程), 实际差压可能超过 $1.5 \mathrm{kPa} 。 1^{\#}$ 机组出现 满负荷 $300 \mathrm{MW}$ 运行时，电除尘后部 2 台引风机及引风机后 部 1 台增压风机全出力状态下出受限, 引风机近失速区运行 多次引发喘振。
(2) $1^{\#}$ 炉出现机组出力受限 (285MW), 无法带满负荷 $300 \mathrm{MW}$; 烟气温降约 $20^{\circ} \mathrm{C}$ ( 原设计值为 $43^{\circ} \mathrm{C}$ ), 净烟气温度约 $56^{\circ} \mathrm{C}$, 低于设计值 $63^{\circ} \mathrm{C}$ 。

(3)由于堵灰造成 2 台引风机和 1 台增压风机电流增加, 4 台机组厂用电每年共增加约 $2.88 \times 10^{6} \mathrm{~kW} \cdot \mathrm{h}$ 。

(4) MGGH 检修时烟气冷却器需要用高压水进行清洗以 恢复其性能, 增加维护费用。

(5)高压水冲洗后, 两侧封板内进灰水, 易导致烟气冷却 器弯头腐蚀。检修时大量更换弯头, 同时配套的脚手架、保温 拆装人工费用支出较大。

\section{3 设备吹灰器改造进程}

(1)为解决堵灰造成差压大, $3^{*}$ 炉于 2019 年检修中将原 有 DSK-7 型更换为 DFQ-75W 声波吹灰器, 起到一定的效 果, 烟冷器差压 $300 \mathrm{MW}$ 工况下约 $1.0 \mathrm{kPa}$ 。

(2) $4^{*}$ 炉于 2020 年 1 月 1 日检修后投运，此次检修更换 8 台浴轮低频大功率声波吹灰器, 安装于 2 组烟气冷却器中 间。运行期间烟冷器差压 300MW 工况下约 $0.8 \mathrm{kPa}$ 。

(3)继 4* 炉 MGGH 烟气冷却器加装 8 台浴轮低频大功率 声波吹灰器效果明显后, $1^{\#}$ 炉 MGGH 烟气冷却器在同样位 置也加装了同型号同数量的声波吹灰器, 并在第 2 组烟气冷 却器后部增加 4 台相同的声波吹灰器, 效果明显, 烟气冷却 器运行差压降至 $0.45 \mathrm{kPa}$, 取得了预期的效果。

\section{4 设备吹灰器改造后取得的成果}

\subsection{4 \#机组改造后取得的成果}

安装低频大功率声波吹灰器后 $4^{\#}$ 机组积灰情况好转。 $4^{\#}$ 机组于 4 月 8 日停运后现场检查, MGGH 烟气冷却器积灰情 况明显比修前好很多。

\section{$4.23^{\#}$ 机组改造后取得的成果}

$3^{\#}$ 炉未安装低频大功率声波吹灰器有改善但相较 $4^{*}$ 机 组效果差。 $3^{*}$ 炉与 $4^{\#}$ 炉声波使用情况对比: $3^{\#}$ 炉烟冷器积灰 堵灰情况比 $4^{\#}$ 炉严重一些, $3^{*}$ 炉烟道底部积灰平均厚度 $500 \mathrm{~mm}, 4^{\#}$ 炉烟道底部积灰平均厚度 $100 \mathrm{~mm}, 4^{\#}$ 炉声波吹灰 器使用效果明显好于 $3^{\#}$ 机组。

详见比对情况（改造前后及 $3^{\#} 、 4^{\#}$ 炉比对）照片：

$4^{\#}$ 炉原有吹灰器 B2 烟道低省侧模块背风面积灰情况如 图 1 图 9 所示。 


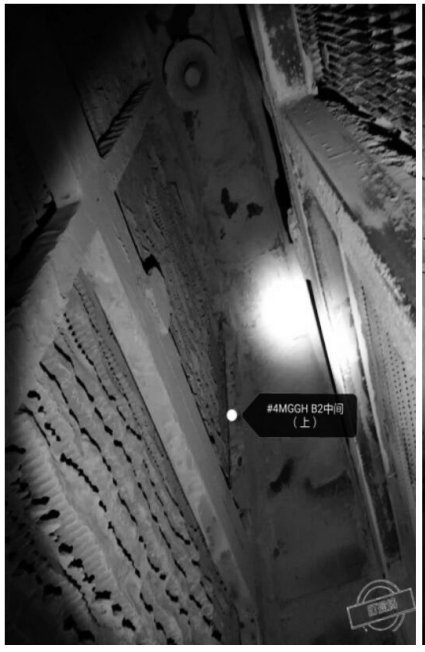

图 1 B2 烟道中上部 1

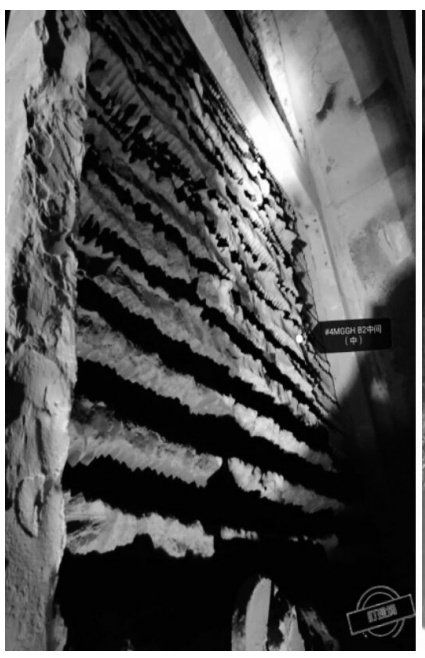

图 4 B2 烟道中部 1

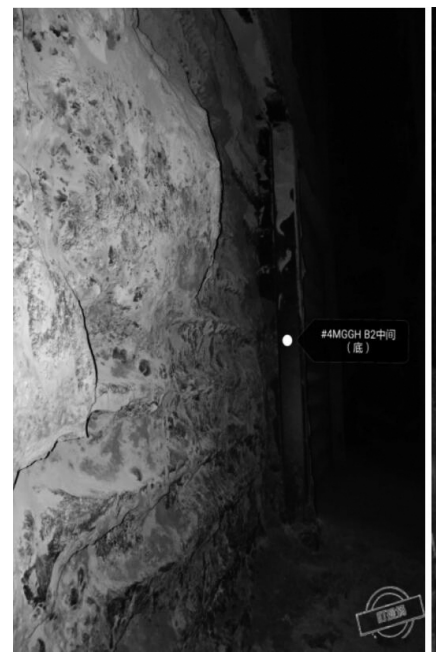

图 7 B2 烟道下部 1

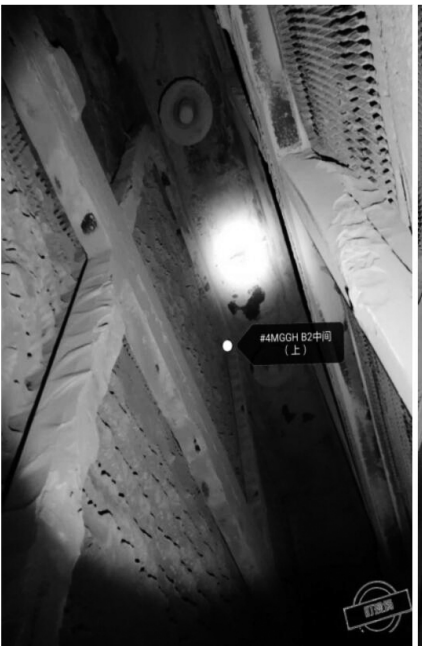

图 2 B2 烟道中上部 2

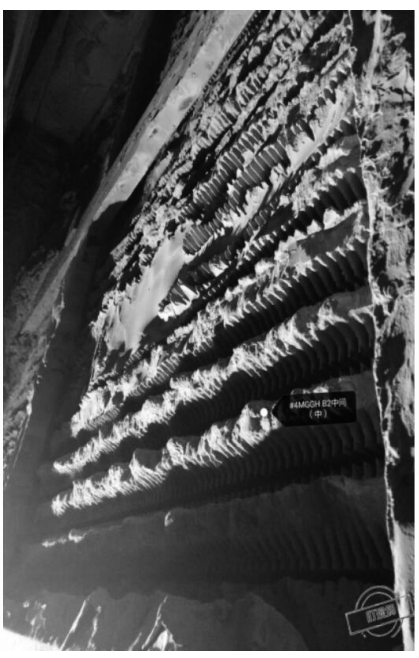

图 5 B2 烟道中部 2

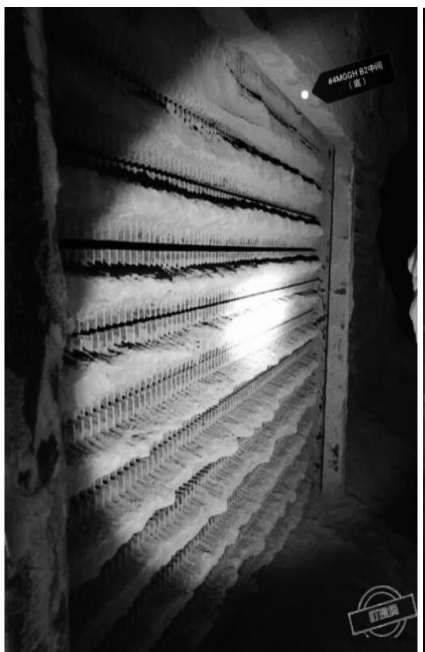

图 8 B2 烟道下部 2

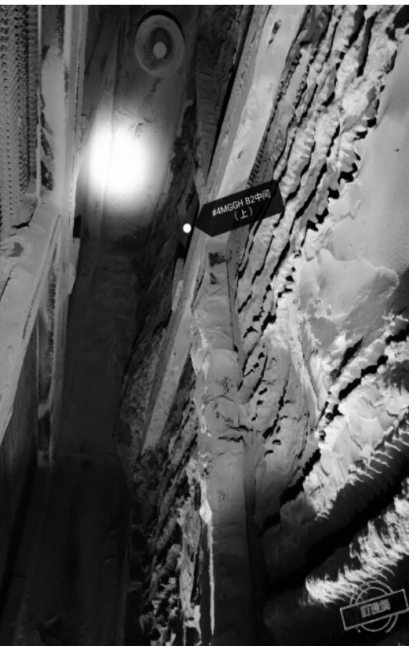

图 3 B2 烟道中上部 3

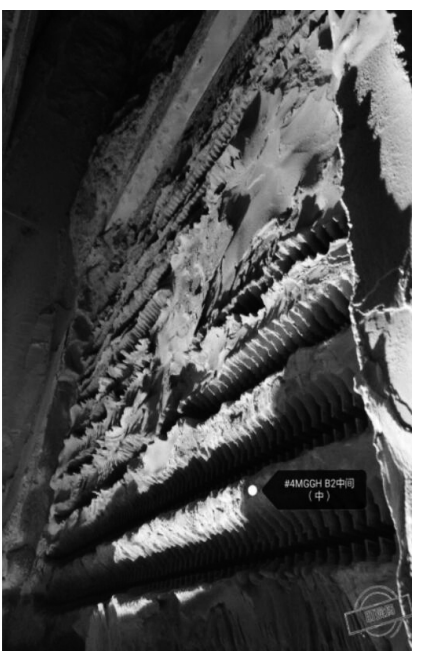

图 6 B2 烟道中部 3

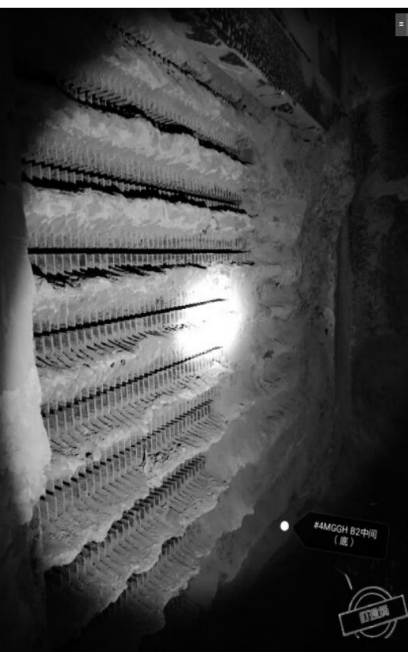

图 9 B2 烟道下部 3
4 \# 炉更换新吹灰器后 B2 烟道低省侧模块背风面积灰情 况如图 10 图 18 所示。
4.31 \#炉改造后取得的成果

目前, $1^{\#}$ 炉运行中暂无法查看 MGGH 烟气冷却器积灰情 


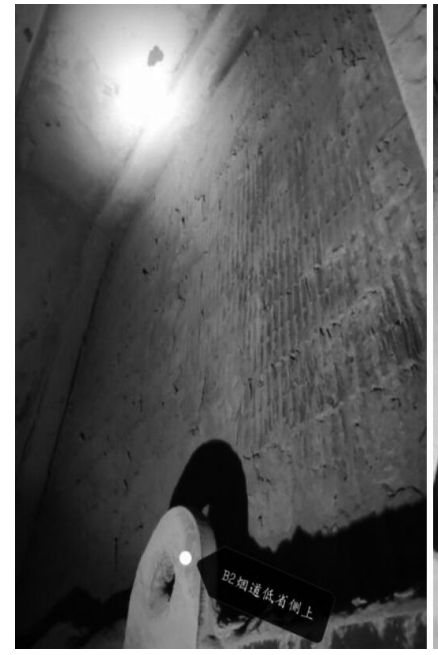

图 10 B2 烟道上部 1

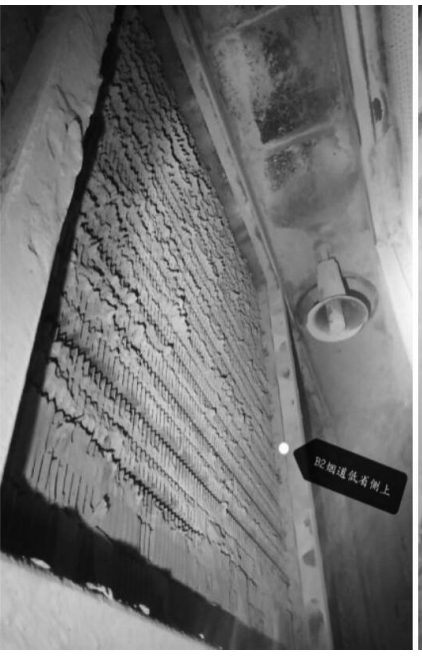

图 11 B2 烟道上部 2

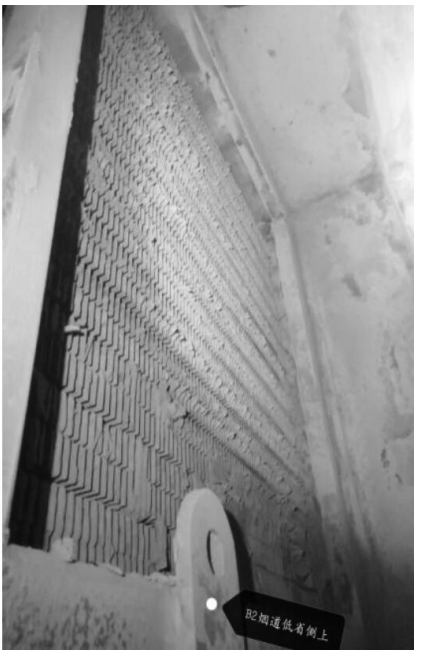

图 12 B2 烟道上部 3
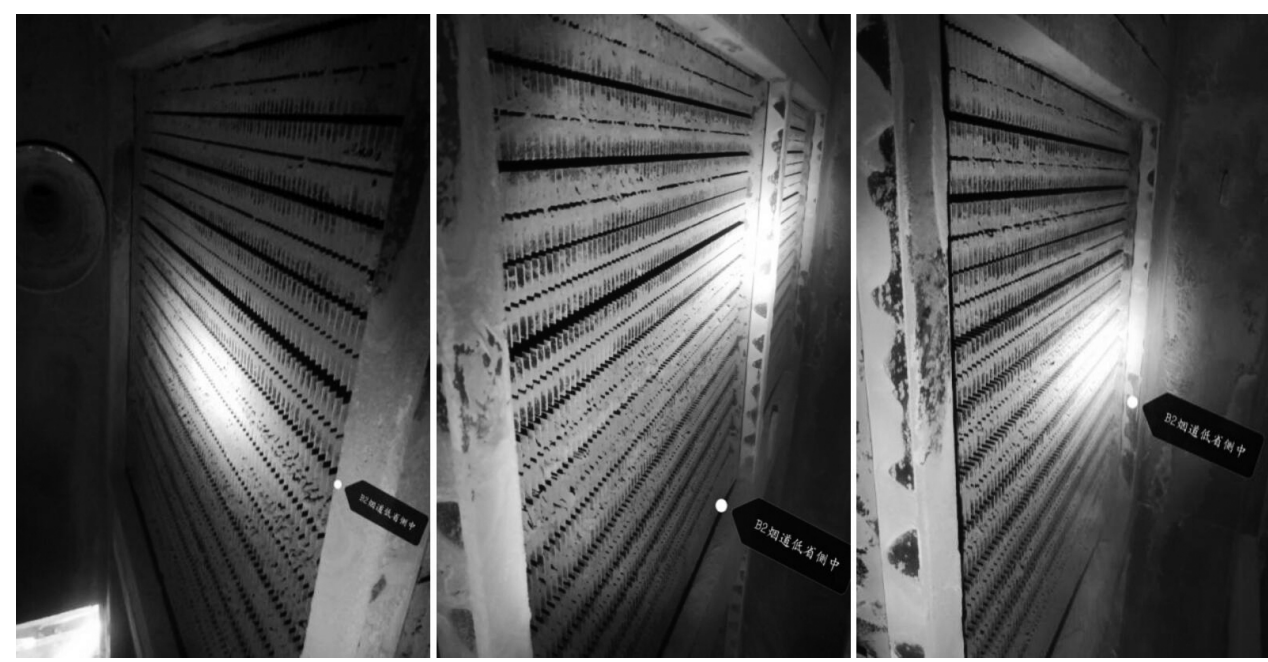

图 13 B2 烟道中部 1

图 14 B2 烟道中部 2

图 15 B2 烟道中部 3
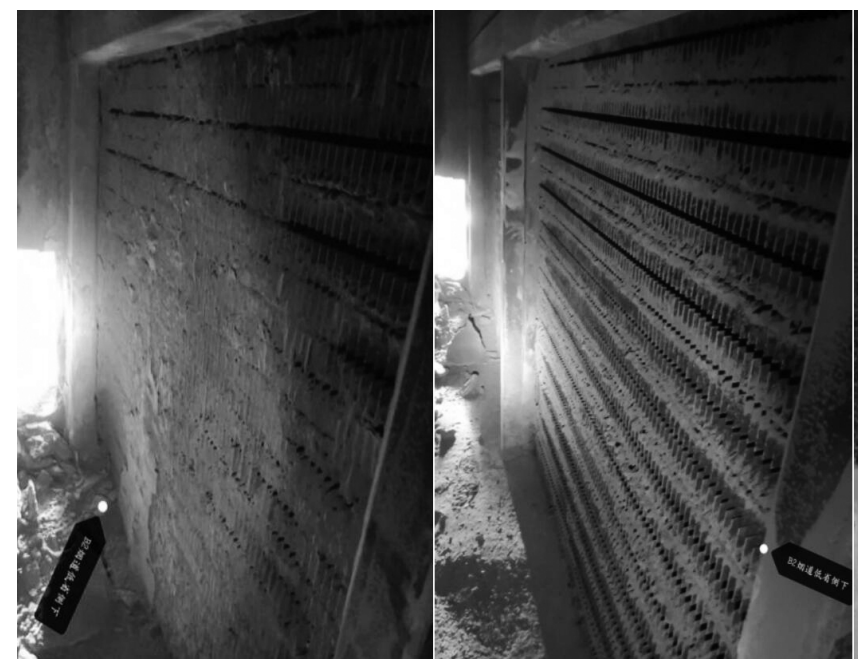

图 17 B2 烟道下部 2

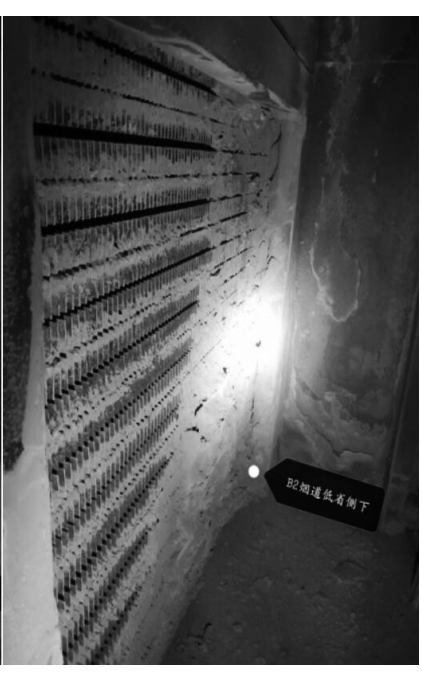

图 18 B2 烟道下部 3

图 16 B2 烟道下部 1 $1^{\#}$ 炉改造前 2 台引风机 +1 台增压风机电流情况如图 19 况, $1^{\#}$ 炉 $4^{\#}$ 炉 MGGH 烟气冷却器运行差压分别为 $0.45 \mathrm{kPa} /$ 所示。 


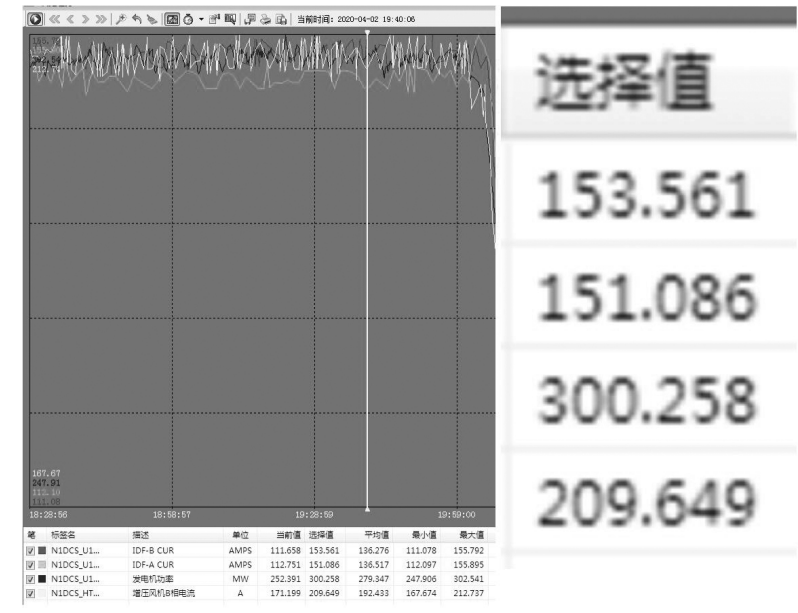

图 19 修前风机 SIS 数据

由图 19 可见, $1^{\#}$ 炉 $300 \mathrm{MW}$ 下 2 台引风机 +1 台增压风 机总电流 $=153.5+151.1+209.6=514.2 \mathrm{~A}$ 。

$1^{\#}$ 炉改造后 2 台引风机 +1 台增压风机电流情况如图 20 所示。

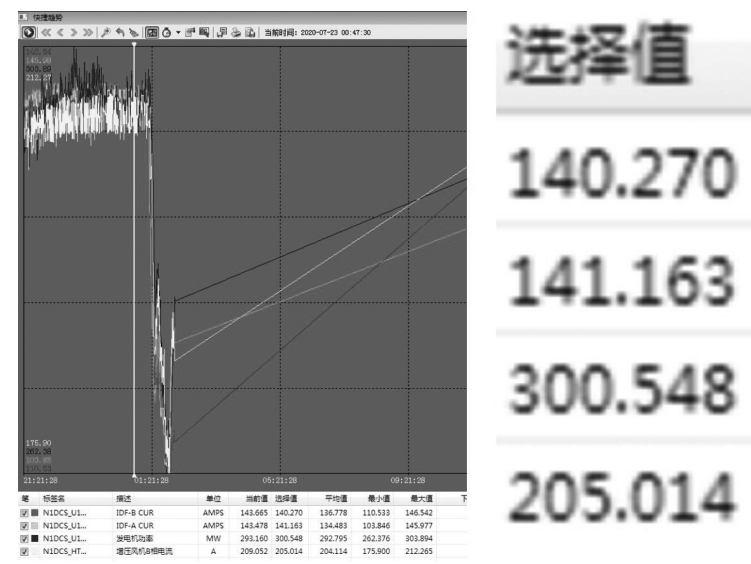

图 20 修后风机 SIS 数据

由图 20 可见, $1^{\#}$ 炉 $300 \mathrm{MW}$ 下 2 台引风机 +1 台增压风 机总电流 $=140.2+141.2+205=486.4 A$ 。

改造前后 $1^{\#}$ 机组 $300 \mathrm{MW}$ 满负荷状态下运行电流节电 514.2-486.4=27.8A, 综合考虑修前修后空预器、SCR 脱硝反 应器差压均有所下降, MGGH 烟气冷却器带来的 2 台引风 机+1 台增压风机电流节约比例约 50\%即 13.9A。

\section{4 后续公司因 $M G G H$ 烟气冷却器改造带来的附 加成果}

(1)降低此前为清理 MGGH 烟气冷却器积灰投入的高压 水冲洗费用每年约 60 万元; 每年节约高压水冲洗造成弯头 更换及配合弯头更换投入的脚手架搭设、保温拆装费用约 40 万元。目前, $1^{\#}$ 炉改造后 MGGH 烟气冷却器差压很小, 后
续高压水冲洗项目可以取消。

(2)MGGH 烟气冷却器弯头腐蚀的关键在于水冲洗后, 灰 水由管排与封板间隙进入弯头部位, 灰水腐蚀弯头, 弯头漏 水后流至烟道内更加剧管排堵塞，长时间运行后灰块变硬， 检修时高压水无法进行清理。因此,加装浴轮低频大功率声 波吹灰器可以解决此项问题。

(3)由于 MGGH 烟气冷却器安装标高约 $19 \mathrm{~m}$, 此处作业属 高处作业, 加装涡轮低频大功率声波吹灰器可以带来相应的 安全效益。

图 21、图 22 为厦门华夏国际电力发展有限公司 SIS 运 行画面截图(满负荷 300MW)。
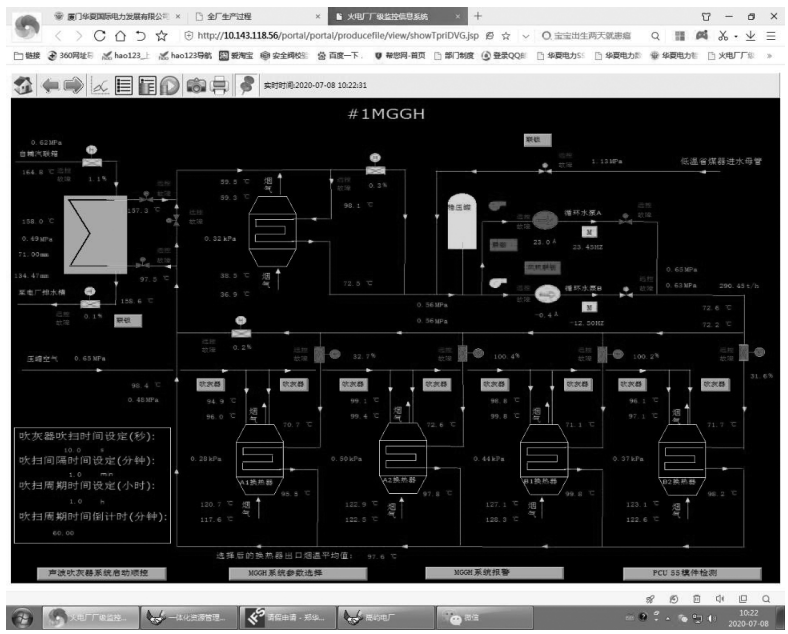

图 211 \#机组改造后 SIS 画面 (差压很小)

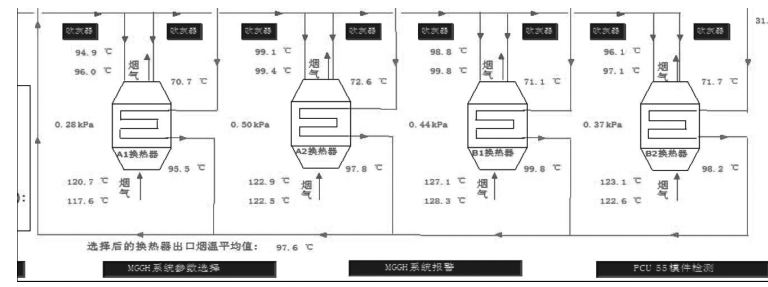

图 22 1"机组改造后 SIS 画面 (局部放大可见差压很小)

\section{5 结语}

厦门华夏国际电力发展有限公司 MGGH 烟气换热器后 部为低低温电除尘, 原先考虑用蒸汽吹灰方式, 因蒸汽吹灰 会增加低低温电除尘水分, 水分增加对灰流动性不利, 同时, 蒸汽吹灰会吹损 MGGH 烟气冷却器, 且安装蒸汽吹灰的空间 狭小,传热元件非常密集, 蒸汽吹灰无法吹到所有管排,安装 后不利于设备检修, 故而选用浴轮低频大功率声波吹灰器。

$1^{\#}$ 锅炉采用生产的涡轮低频大功率声波吹灰器对 (下转第 61 页) 


\section{4 改造方案}

为缩短电站沉砂池冲砂作业时间, 抢发电量, 公司安生 部与电站人员就多泥沙电站冲砂展开研究与优化, 经反复论 证, 最终采用“钢板围挡”方案( 见图 6), 该方案全面借用了 “都江堰鱼嘴”分砂原理, 同时咨询了相关水工专业设计人员, 采用在渠首进水口工作闸后端装设高 $50 \mathrm{~cm}$ 钢板桩, 使之形成 冲砂分流嘴达到“束水冲砂”的效果, 增加沉砂池提高单孔闸 门的冲泄力度、加强水量的高效利用。该方案巧妙利用水力特 点, 成功实现了淤沙到指定位置、冲砂快速有效的目的。

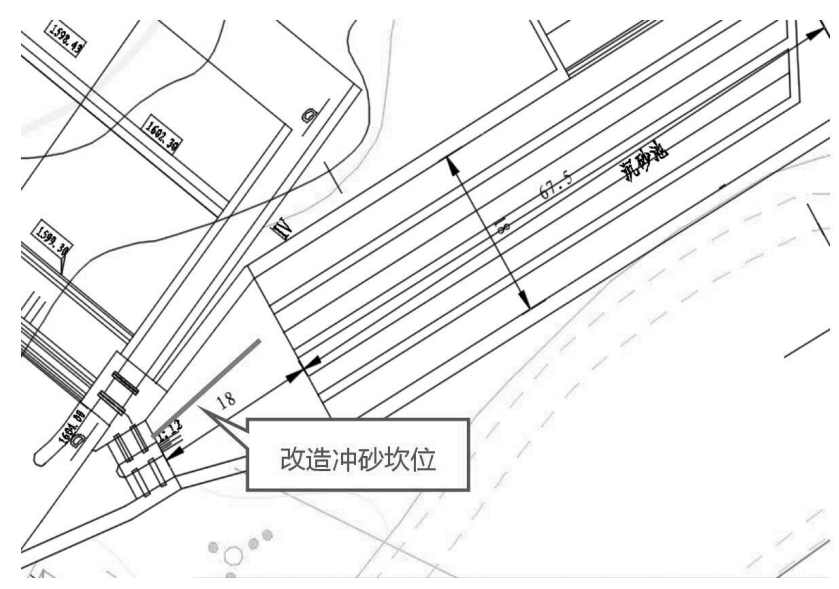

图 6 冲砂设施改造布置

经在渠首进水口工作闸后端加装冲砂设施后, 充分调节 冲砂泄洪闸门开度, 利用冲砂分流嘴控制汇流进入沉砂池的 水流, 加大控制流速与水流压力, 加快了沉砂池冲泄效率。

\section{5 运行效果}

共和电站沉砂池冲砂系统改造于 2020 年 6 月 15 日完 成改造安装与验收。自投入使用以来, 冲砂系统改造取得了 明显效果, 大幅缩短了电站汛期停机冲砂时长。

\section{（上接第 48 页）}

MGGH 烟气冷却器积灰清理取得预期效果, 后续将进一步对 其他机组参照 $1^{\#}$ 炉进行改造。全部改造完成后每年节约维 修费用将超过 100 万元, 节约电量约 $2.30 \times 10^{6} \mathrm{~kW} \cdot \mathrm{h}$ 。

厦门华夏国际电力发展有限公司 $\mathrm{MGGH}$ 烟气冷却器加 装涡轮低频大功率声波吹灰器就地设有控制柜, 吹灰器的吹 扫时间、间隔时间均可灵活调节, 同时接入 DCS 进行操作及
自进入 2020 年 7 月汛期, 共和电站共计进行了 2 次停 机冲砂作业平均耗时约 2.75h (见表 2)。对比过去 3 年停机 冲砂记录 $8.2 \mathrm{~h}$ 。经过此次沉砂池冲砂系统改造大幅缩短了冲 砂停机所需时间, 综合对比耗时缩短了 $70 \%$ 以上。根据汛期 电站实际运行工况, 每次停机冲砂可缩短约 5 6h, 可增加电 量约 $1.62 \times 10^{5} \mathrm{~kW} \cdot \mathrm{h}$ 。

表 2 冲砂设施改造后时长

\begin{tabular}{ccccc}
\hline 序号 & 年份 & 日期 & 起止时间 & 冲砂耗时 $/ \mathrm{h}$ \\
\hline 1 & 2020 年 & 7 月 13 日 & 7:30 10:00 & 2.5 \\
2 & 2020 年 & 7 月 20 日 & 11:00 15:00 & 3 \\
\hline
\end{tabular}

\section{6 技术分析}

共和电站沉砂池冲砂系统改造, 在总结过去电站汛期沉 砂池淤积严重, 直接影响电站机组涉水部件安全运行的基础 上, 通过实地踏勘与参考学习其他较为科学成熟的冲砂方案 下, 制订了共和电站冲砂技术改造方案, 方案主要特点:

借用 “都江堰鱼嘴”分沙原理, 巧妙利用鱼嘴控制分流水 力特点, 调节控制进入沉砂池的水流流速与压力, 高效利用 水力快流速流动可附带冲击堆积的显著特点, 实现了对淤积 体冲泄至指定区域、冲砂快速有效的目的。

\section{7 效益分析}

共和电站渠首沉砂池冲砂系统改造完成后, 大幅度缩短 了停机冲砂时长。经完成近 2 次冲砂作业分析, 将冲砂时长缩 短至 3 4h 且冲洗更为彻底。比原冲砂方式节省时间 5 6h, 每 次停机冲砂相比改造前可增加发电量约 $1.62 \times 10^{5} \mathrm{~kW} \cdot \mathrm{h}$ 。按每 月 4 次计算, 全年丰水期 (7 10 月)预计可增加发电量约 3x $10^{6} \mathrm{~kW} \cdot \mathrm{h}$ 时, 直接增加电量收益约 $60 \sim 70$ 万元。

故障报警, 设备稳定运行及使用性能进一步得到保障。投运 后涡轮低频大功率声波吹灰器运行可靠性较好、故障低。

\section{参考文献}

[1] 张峰.声波吹灰器在锅炉吹灰中的应用研究[J].电声技术,2018, $42(3): 25-27$

[2] 赵旺初.声波吹灰器的原理与应用[J]. 电力建设,2001(1):54-56. 